\title{
The Hanging/Hanged patient and Relevance to Pre-Hospital Care
}

\author{
Karen Gubbins MSc, PGCert, BSc, FHEA
}

\begin{abstract}
Death and injury from hanging is a complex situation, which requires careful and appropriate assessment and management in the pre-hospital environment. It is arguably an area of limited understanding and therefore may not be assessed and managed in the most effective manner. Most hanged/hanging patients will be found in their homes, rather than in institutions. It could be argued that due to prevalence as a suicide method, the majority of pre-hospital ambulance service staff will be responded to at least one hanged or hanging patient within their careers, thus a greater understanding will benefit both clinician and patient. Patients who attempt or achieve suicide will rarely achieve fracturing the spine and severing the spinal cord, bringing into question the requirement for the traditional cervical collar and spinal immobilisation techniques. Death from asphyxiation and carotid/vagal reflex require consideration and management as does raised ICP, which is likely to occur.
\end{abstract}

\section{Key words}

Hanging, hanged, suicide, prehospital care, asphyxiation, vagal reflex, carotid reflex, ALS

\section{Key Points}

Most hanging/hanged patients are found in their homes Asphyxiation is the most common cause of death in hanging Fracture to cervical spine in hanging is not as common as asphyxiation Cervical spine immobilisation with cervical collar may increase already raised ICP Consider $\mathrm{C}$ spine immobilisation based upon the mechanism of injury - do not assume it is required in all cases. 


\section{Background}

Hanging is one of the most common suicide methods in England \& Wales (Lost all Hope 2016), with $51.7 \%$ of suicides (and deaths likely but not proven to be suicide) being by hanging. Over 4200 people ending their lives by suicide in 2010 (department of Health 2012). These figures suggest around 2171 people hanged themselves in 2010. Gunnell et al (2005) propose that hanging is one of the most lethal forms of suicide attempt and they estimate the fatality being around $70 \%$. Bennewith et al (2005) state that suicide by hanging in prison or psychiatric units account for only $6 \%$ of the total hanging suicides in the 6 month period and locations they studied. Thus, $94 \%$ of hanging suicides take place in the community, potentially in people's homes or workplaces. Bennewith et al (2005) further divide the locations see table 1.

Table 1

\begin{tabular}{|l|l|}
\hline \multicolumn{1}{|c|}{ Location } & $\%$ \\
\hline In their home & $65.4 \%$ \\
\hline In public areas & $16.6 \%$ \\
\hline Unaccounted for & $18 \%$ \\
\hline
\end{tabular}

They also categorise the items used for the hanging see table 2: these items can clearly be identified by their common place availability and ease of access. The ease of access to these household items can make prevention difficult for the person regardless of whether the attempt is an impulsive one or a planned one.

\begin{tabular}{|l|l|}
\hline \multicolumn{1}{|c|}{ Items used } & \multicolumn{1}{c|}{$\%$} \\
\hline Rope or cord & $49.4 \%$ \\
\hline Belt & $13.1 \%$ \\
\hline Electrical cable & $11.9 \%$ \\
\hline $\begin{array}{l}\text { Other clothing (scarf, } \\
\text { ties, dressing gown cord, } \\
\text { shoelaces) }\end{array}$ & $10 \%$ \\
\hline Dog lead & $6.3 \%$ \\
\hline
\end{tabular}


Karanth and Nayyar (2005) identifies the gender split of hanging suicides as being almost equal, showing 19 males compared to 18 females,. This is in contrast to overall suicide figures, where the Department of Health (2012) state "Men are at three times greater risk of suicide than women", and that "Men aged 35-49 are now the group with the highest suicide rate".

The location of the majority of hanging suicides being at home and not in a medical institution (Bennewith et al 2005), suggests that it is likely that ambulance crews will attend a number of these incidents within their careers. Thus, it is important for paramedics and indeed all ambulance staff to understand the nature of injuries and their management. There is limited research and evidence for the management of the hanged patient in the prehospital environment. This paper will draw from the available research to suggest the most appropriate course of action, however it is recognised that more research is required to ensure best practice is found in the future.

\section{Definition}

Hanging can be categorised as judicial or non-judicial, with the former being a legal capital punishment, which usually follows a set procedure in order to cause death. Currently, it is argued that hanging is the most frequent forma of judicial capital punishment, with approximately 60 countries 'authorized' to utilise, although may not practice, this form of capital punishment (Cornel Law School 2016). Death from hanging (judicial or non-judicial) can be cause by a number of reasons, strangulation, carotid/vagal reflex or fracturing the cervical spine causing severe damage to the spinal cord (CapitalPunishmentUK.org undated). 'Hanging' by definition results in the death of the individual, however, 'Near hanging' differs in that the individual survives to admission to hospital (Adams 1999).

\section{Context}


Judicial hanging was abolished in the UK in 1969 (British Broadcasting Company 2013), therefore the only hanging that UK ambulance crews should attend is suicide, murder or autoerotic asphyxiation. Suicide is the deliberate process of taking one's own life (NHS Choices Undated, murder is defined as the unlawful killing of a human being by another, with malice aforethought (Oxford University Press 1996) and autoerotic asphyxiation is the intentional production of a state of hypoxia or even anoxia to heighten sexual pleasure (Cowell 2009). Anecdotally, the number of paediatric suicides and accidents by hanging has increased over the past 3-4 years, thus potentially, ambulance crews could attend such a case. According to Deasy et al 2012), sadly, out of hospital hangings have a $83 \%$ mortality.

\section{Pathophysiology of hanging/near hanging}

\section{Strangulation}

Asphyxiation is the cessation of gaseous exchange (National Association of Emergency Medical Technicians 2010), In the case of hanging or near hanging, this could result from an increase in pressure on the trachea or fracture of the larynx, resulting in the compression of the larynx. It can also result from the backwards pressure of the tongue obstructing the airway. In essence, the patient has an airway obstruction from one source or another. Strangulation however, is the closure of blood vessels and/or airways as a result of external pressure applied to the neck (Morild 1996), therefore, strangulation, incorporates some elements of asphyxiation.

\section{Carotid/vagal reflex}

Vagal stimulation has been shown to induce cardiac arrest, by initially inhibiting the action of the Sino-Atrial (SA) node in the heart (Vassalle et al 1967). This then leads on to the suppression of any ventricular pacemakers, ceasing any electrical activity in the heart (Vassalle et al 1967). This work has been supported by Vaseghi and Shivkumar (2008), who state "Substantial evidence links enhanced sympathetic activation with ventricular arrhythmias and sudden cardiac death." 


\section{Fracturing the cervical spine}

The 'Hangman's fracture' (traumatic spondylolisthesis of C2 (Xin-Feng et al 2006)) is usually sustained as a direct result of distraction and hyperextension of the cervical spine region. It usually results in the movement of the vertebrae at $\mathrm{C} 2$. It is suggested that the 'Hangman's fracture' occurs rarely in hanging, being more frequent in vehicular, diving and falling incidents (Fielding et al 1989). However, rarely, does not mean it does not occur. Fielding et al (1989) suggest that it is most likely to occur where the knot (or joining of the loop is placed under the person chin, forcing the head backwards. This is in support of Wood-Jones (1913), who suggests that should the knot be suboccipital (behind the head), it is most likely that the individual would be strangled. The movement and potential fracture of C2 can cause catastrophic damage to the spinal cord (Sköld 1978) and therefore result in death.

The actual cause of death can be considered to be related to the type of hanging that occurs as seen in table 3. It can also been seen, that the majority of suicides through hanging are unlikely to be 'long drop', therefore suggesting fracture to the cervical vertebrae/spinal cord experienced is likely to be uncommon.

Table 3

\begin{tabular}{|l|l|}
\hline $\begin{array}{l}\text { Short drop } \\
\text { Usually a short distance fallen by the 'victim' } \\
\text { weight of noose/ligature presses in to the neck }\end{array}$ & $\begin{array}{l}\text { Cause of death is usually asphyxiation, or } \\
\text { Carotid/vagal reflex }\end{array}$ \\
\hline $\begin{array}{l}\text { Suspension hanging } \\
\text { Victim is lifted into the air to allow the weight to } \\
\text { be suspended as in short drop }\end{array}$ & $\begin{array}{l}\text { Cause of death is usually asphyxiation, or } \\
\text { Carotid/vagal reflex }\end{array}$ \\
\hline $\begin{array}{l}\text { Standard drop } \\
\text { A drop of 4-6 feet is ensured }\end{array}$ & $\begin{array}{l}\text { Cause of death is can be asphyxiation, or } \\
\text { Carotid/vagal reflex OR fracture to the cervical } \\
\text { vertebrae/spinal cord }\end{array}$ \\
\hline $\begin{array}{l}\text { Long drop } \\
\text { Drop height is calculated by height and weight of } \\
\text { the victim }\end{array}$ & $\begin{array}{l}\text { Death is usually caused by fracture to the } \\
\text { cervical vertebrae/spinal cord }\end{array}$ \\
\hline
\end{tabular}




\section{Pre-hospital management of the hanging/hanged patient in cardiac arrest}

There are few guidelines presented for the pre-hospital management of the hanging/hanged patient, and most have been published some 20-30 years ago.

Iserson (1984) recommends:

1. Cut off ligature (avoiding the knot or connection at the loop)

2. Stabilisation of the cervical spine

3. $A B C$ ventilate as needed, position to prevent aspiration if breathing is present

4. Cardiac monitoring

5. IV access and administer $D^{5} 0.45 \mathrm{NS}$ ( $5 \%$ dextrose and $0.45 \%$ saline infusion)

6. Manage raised ICP if present

7. Collect other information e.g. history

Many of these points could still be considered valid today. There is however, no mention of circulatory support using cardiopulmonary resuscitation. It has been documented that even patients in a state of profound unconsciousness can have a positive outcome if they are managed correctly (Bautz and Knottenbelt 1994).

More recent research (Mobbs et al 2002) suggests that ridged cervical collar application can increase intercranial pressure in patients' with brain trauma. It could be construed that in the hanging/hanged patient, hypoxia is a real risk, which can lead to brain injury (Arciniegas 2012), thus the use of the rigid collar should be evaluated carefully. In cases of brain and cervical spine injury, Mobbs et al (2002) also suggest the use of sandbags either side of the patient's head taped to the bed, without the use of a collar.

Based upon the research within, it could be considered that a more effective management of the unconscious hanging victim could be:

1. Reduce patients weight from the neck if possible (by supporting manually) 
2. Maintain C-spine stability - consider the use of a cervical collar to support head if available quickly (to avoid creating a $\mathrm{C}$ spine injury by loss of head control)

3. Cut off the ligature or suspending cord

4. Maintain head control and lower the patient to the floor or trolley

5. Consider the needs for $\mathrm{c}$ spine immobilisation - is the patient likely to have damaged the $\mathrm{c}$ spine based upon the circumstances (i.e. a patient who has hanged themselves by dropping from a loft hatch is much more likely than one who has tied the ligature to a curtain rail and then knelt down).

6. Check and manage ABCs - consider early use of intubation in case of airway swelling due to trauma

7. Supply ventilations and cardiac compressions as necessary (apply current ALS guidelines)

8. Consider if the use of a cervical collar could aggravate any raised ICP

9. If cervical spine injury is likely, consider the use of sandbags/head blocks without the use of a collar

\section{Limitations}

This paper has considered contemporary evidence where available, however, specific research would be beneficial in terms of identifying best practice with this groups of patients. In addition, The paper does not consider the additional challenges that may be present in a conscious hanged patient.

\section{References}

Adams N (1999) Near Hanging. Emergency Medicine. Vol 11, pp.17-21

Arciniegas D (2012) Hypoxic-ischemic brain injury. Accessed 11/04/14 from: http://www.internationalbrain.org/articles/hypoxicischemic-brain-injury/

Bautz P, Knottenbelt J (1994) Successful resuscitation from suicidal hanging: report of three cases. Injury. Vol 25, No 2, pp.111-112

Bennewith O, Gunnell D, Kapur N, Turnbull P, Simkin S, Sutton S, Hawton K (2005) Suicide by hanging: multicentre study based on coroners' records in England. British Journal of Psychiatry. Vol 186, pp.260-261

British Broadcasting Company (2013) 16 December. Accessed 24/10/15 from: http://news.bbc.co.uk/onthisday/hi/dates/stories/december/16/newsid 3258000/3258437.stm

CapitalPunishmentUK.org (undated) Hanged by the Neck Until Dead! The Process and Physiology of Judicial Hanging. Accessed 24/10/13 from: http://www.capitalpunishmentuk.org/hanging2.html

Cornell Law School (2016) Methods of Execution. Accessed 14/04/16 from: http://www.deathpenaltyworldwide.org/methods-of-execution.cfm 
Cowell D (2009) Autoerotic Asphyxiation: Secret Pleasure--Lethal Outcome? Pediatrics. Vol 124, pp.1319-1324

Deasy C, Bray J, Smith K Bernard S, Cameron P (2012) Hanging-Associated Out of Hospital Cardiac Arrests in Melbourne, Australia. Emergency Medical Journal . Vol 30, No 1, pp.38-42

Department of Health (2012) Preventing suicide in England: A cross-government outcomes strategy to save lives. Department of Health: London

Fielding J, Francis W, Hawkins R, Pepin J, Hensinger R (1989) Traumatic spondylolisthesis of the axis. Clinical Orthopaedics and Related Research. Feb (239) pp.47-52

Gunnell D, Bennewith O, Hawton K, Simkin S, Kapur N (2005) The Epidemiology and Prevention of Suicide by Hanging: A Systematic Review. Internation Journal of Epidemiology. Vol 34, pp.433-442

Iserson K (1984) Strangulation: A Review of Ligature, Manual and Postural Neck Compression Injuries. Annals of Emergency Medicine. Vol 133 March 1984, pp.179-185

Karanth S, Nayyar (2005) What Influences Outcome of Patients with Suicidal Hanging. Journal of the Association of Physicians of India. Vol 53, pp.853-856

Lost All Hope (2016) England \& Wales methods of suicide Accessed 14/04/2016 from: http://lostallhope.com/suicide-statistics/england-wales-methods-suicide

Morild I (1996) Fracture of Neck Structure in Suicidal Hanging. Medicine, Science and the Law. Vol 36, No 1 , pp.80-84

National Association of Emergency Medical Technicians (2010) Military Edition PHTLS $7^{\text {th }}$ Ed. Mosby Elsevier. Missouri

NHS Choices (undated) Suicide. Accessed 24/10/15 from:

http://www.nhs.uk/Conditions/Suicide/Pages/Introduction.aspx

Oxford University Press (1996) Oxford English Dictionary. Oxford University Press: Oxford

Sköld G (1978) Fractures of the Axis Caused by Hanging. Rechtsmedizin. Vol 80, pp.329-331

Vaseghi M, Shivkumar K (2008) The Role of the Autonomic Nervous System in Sudden Cardiac Death. Progress in Cardiovascular Diseases. Vol 50, No 6, pp.404-419

Vassalle M, Caress D, Slovin A, Stuckey J (1967) On the Cause of Ventricular Asystole during Vagal Stimulation. Circulation Research. Vol 20, pp.228-241

Wood-Jones F (1913) The Ideal Lesion Produced by Judicial Hanging. The Lancet. Vol 181. No 4662, pp.53

Xin-Feng L, Li-Yang D, Hua L, Xiao-Dong C (2006) A systematic review of the management of hangman's fractures. European Spine Journal. Vol 15, No 3, pp.257-269 